\title{
Promoting gender equality in the Eastern Neighbourhood region
}

Sue Enfield

Institute of Development Studies

10 March 2021

\section{Question}

What are the drivers and opportunities for promoting gender equality in the Eastern Neighbourhood region? What examples are there of affecting change, and how have these initiatives contributed to stability?

\section{Contents}

1. Summary

2. Drivers and opportunities for promoting gender equality in the Eastern Neighbourhood region

3. Opportunities for Eastern Neighbourhood countries

4. Examples of programmes designed to affect change in gender equality

5. References

The K4D helpdesk service provides brief summaries of current research, evidence, and lessons learned. Helpdesk reports are not rigorous or systematic reviews; they are intended to provide an introduction to the most important evidence related to a research question. They draw on a rapid deskbased review of published literature and consultation with subject specialists. 


\section{Summary}

Although equality between women and men is enshrined in the constitutions and legal systems of all Eastern Neighbourhood countries, and all countries have ratified most of the important international conventions in this area without reservations; women are still subject to social discrimination (Gabriel, 2016). Discriminatory laws, social norms and practices rooted in patriarchal systems inherited from the Soviet era have negative consequences and act as drags upon gender equality. Former Soviet states making the transition from a command economy to a market driven system need to make changes in governance and accountability systems to allow for women to have agency and to benefit from any nominal status of gender equality (Shankland \& MacGregor, 2018). This report considers areas where there are outstanding opportunities to improve women's situation in Eastern Neighbourhood countries.

Over the period from 2014 to 2019 there has been a positive shift towards lower levels of gender discrimination from analysis based upon formal and informal laws, social norms and practices that restrict women's and girls' rights, as well as their access to empowerment opportunities and resources (OECD Social Institutions and Gender Index, 2014 \& 2019). Nevertheless, the literature illustrates gaps between women's rights, their representation and collective voice, and the real level of gender equality that is enjoyed in various domains. The interpretation of this rapid review is that these disparities offer opportunities to redress these gaps Examples given in this rapid review of the literature are illustrative and not exhaustive. The focus for this review has been on Armenia, Azerbaijan, Georgia and Moldova.

Several international legal standards are adopted and passed into law, without women necessarily having the protection these describe (CEDAW ${ }^{1}$ for example, while domestic and other forms of gender-based violence (GBV) remain a priority for attention across the region). Near equal levels of literacy and some outstanding areas of equality in access to tertiary education do not lead to equal engagement of women and men in all work sectors; nor to equal levels of pay or seniority within organisations. In some situations of conflict, women have played an active role in peacebuilding yet still find their efforts to build stability thwarted by political forces or from degeneration into further conflicts. Their activism during periods of civil unrest or conflict does not translate into adequate representation in political structures and in government.

UN Women (2017) provides a framework of actions and interventions that have demonstrated impact in reducing gender gaps and promoting gender equality and women's empowerment, all aspects of which remain relevant to Eastern Neighbourhood countries

- Tackling adverse norms and promoting positive role models

- Ensuring legal protection, addressing GBV and reforming discriminatory laws

- Recognising, reducing, and redistributing unpaid work and care

- Building assets - digital, financial, property and information

- Changing business and employment culture and practice

- Strengthening visibility, collective voice, and representation

\footnotetext{
${ }^{1}$ Convention on the Elimination of All Forms of Discrimination against Women
} 
Tackling adverse norms and promoting positive role models in employment culture and practice is a major opportunity to address women's economic empowerment Women across eastern neighbourhood countries do not enjoy equal access to paid work. Significantly less women than men take part in the labour market and the gender pay gap remains high. Responsibilities of family care fall unequally on women and discourage and disincentivise even educated women from seeking employment options outside the home. Asthe foundation of the economy varies across countries of the Eastern Neighbourhood active measures to improve women's economic empowerment and address inequality must vary with context. Agriculture employs at least $30 \%$ of the female and male workforce in all countries except Belarus but low productivity of agriculture limits economic gain. Where the level of industrialisation is low, waged employment is a restricted alternative. Women are substantially engaged in entrepreneurial activities across all countries of the region and there is some evidence to suggest that expansion of female managed firms might benefit these economically and generate more female jobs (Khitarishvili, 2016: 17). Gender differences in the ownership and control of property are also major determinants of gender inequality. Strengthening women's access to credit, building their networks and business knowledge, improving access to mobile phones and internet technology all have potential to improve women's participation in enterprise and employment.

\section{Ensuring legal protection, addressing GBV and reforming discriminatory laws is essential to promoting gender equality}

Violence against women is a pervasive issue across the region. Despite, in law, having equal rights (for example as in the right to divorce) women face social barriers to reporting or leaving their abuser, in seeking protection (especially in rural areas) and in accessing the legal system. Ensuring legal protection, addressing GBV and reforming discriminatory laws is essential to promoting gender equality.

Strengthening women's visibility, developing collective voice and representation, recognising women's contribution to peace building may secure fragile gender gains The lives of women in the South Caucasus are subject to tensions between tradition and social change. Tensions between former Soviet powers and emergent states have in some cases led to conflict that reinforces the gendered narrative of women as patriots, providing sons to defend the nation. At the same time feminist narratives have made their way to the South Caucasus, inspiring social transformation and women's activism. In this situation social movements provide an opportunity which have the potential to either reproduce or transform existing gender inequalities, structures, and social belief systems. External support for the large number of women's organisations and NGOs that have developed is a force for change. Although women's involvement in civil society and civic activism does not easily translate into representation in formal politics - so opportunities for agency and expression may not be fully realised.

Achieving strong gender equality outcomes requires adequate, sustained financing in support of gender equality and women's empowerment. Donors should increase support for dedicated programmes with gender equality and women's empowerment as a principal objective (OECD, 2018). At the end of the report some recent programmes targeting gender inequalities in the region are listed. The list is not exhaustive and there is a lack of available data that considers implementation progress and impact. 


\section{Drivers and opportunities for promoting gender equality in the Eastern Neighbourhood region}

\section{Regional context and country distinctions}

Gender equality is the state in which access to rights or opportunities is unaffected by gender. Although equality between women and men is enshrined in the constitutions and legal systems of all Eastern Neighbourhood countries ${ }^{2}$, and all countries have ratified most of the important international conventions in this area without reservations; women are still subject to social discrimination in Eastern Partnership countries (Gabriel, 2016). Gender inequality affects the quality of life of millions of women in every sphere, with consequences for their well-being and their families and communities. (OECD, 2019). Gender equality is important in many domains; women's agency, representation, and access to services such as education, health and employment, and others. Discriminatory laws, social norms and practices rooted in patriarchal systems have negative consequences and act as drags upon gender equality. Large-scale drivers of change in gender norms, are economic change, education, communications, legal change, social and political mobilisation, and conflict (OECD, 2019).

Full analysis of the causes of gender inequalities in the Eastern Neighbourhood is provided in a companion helpdesk report (Carter, 2020). This report looks at some opportunities to improve womens' situation in Eastern Neighbourhood countries and provides examples of recent programmes designed to affect changes to gender equality.

The OECD Social Institutions and Gender Index (SIGI) is used to collect data globally, and periodically report on this cross-country measure of discriminatory social institutions. Countries are ranked from very low to very high level of discrimination in the SIGI. Source data includes formal and informal laws, social norms and practices that restrict women's and girls' rights, as well as their access to empowerment opportunities and resources. It looks at the gaps that discriminatory legislation, attitudes, and practices create between women and men in terms of rights and opportunities. Comparison of data against four dimensions: discrimination in the family, physical integrity, access to productive and financial assets, and civil liberties, may provide a proxy indicator for relative gender equality. Table 1 below indicates status and change ${ }^{3}$ in Eastern Neighbourhood countries (OECD, SIGI 2014 \& 2019):

\footnotetext{
2 Six eastern neighbours of the EU (Armenia, Azerbaijan, Belarus, Georgia, Moldova, and Ukraine) are targets for work to increase stability and resilience of these countries; also called Eastern Partnership (EaP) countries. ${ }^{3}$ Although changes in rankings between 2014 and 2019 should be interpreted with some caution because of methodological differences, see footnote to Annex A 2019 SIGI Index
} 
Table 1: Level of discrimination according to OECD Social Institutions and Gender Index

\begin{tabular}{lll}
\hline & 2014 & 2019 \\
\hline Azerbaijan & High & Low \\
\hline Armenia & High & Low \\
Belarus & Very low & Low \\
Georgia & Medium & Low \\
Moldova & Low & Low \\
\hline Ukraine & Low & Low \\
\hline
\end{tabular}

Source: Information extracted from Annex A Country level SIGI scores for each appropriate year (OECD, SIGI 2014 \& 2019)

It is important to also consider the breakdown of data within these overarching categories as this shows (for example) that the situation for women in Georgia is less good within the family, and in accessing productive and financial resources (medium discrimination) than in terms of physical integrity ${ }^{4}$ and civil liberties (low discrimination). This despite the country being ranked overall at a low level of discrimination (OECD, SIGI 2019).

As a framework, the actions and interventions listed below have demonstrable impact in promoting gender equality and women's empowerment, reducing gender gaps (UN Women, 2017):

- Tackling adverse norms and promoting positive role models

- Ensuring legal protection, addressing GBV and reforming discriminatory laws

- Recognising, reducing, and redistributing unpaid work and care

- Building assets - digital, financial, property and information

- Changing business and employment culture and practice

- Strengthening visibility, collective voice, and representation

While the state can provide for equality (legal frameworks and opportunity) women must also understand their entitlements, feel empowered to reclaim them and have the means to access opportunity on an equal basis (Shankland \& MacGregor, 2018). Thus, it is that gaps arise between the possibility for gender equality and reality of accessing equality, in countries of the Eastern Neighbourhood - presenting opportunities to work to redress these imbalances.

It is not sufficient to posit that services are inclusive or equitable without addressing the societal and organisational barriers that exclude (women and other minorities such as migrants, ethnic and other disenfranchised groups). For example, former Soviet states making the transition from a command economy to a market driven system need to make changes in governance and accountability systems to allow for women to have agency and to benefit from any nominal status of gender equality. This general principle is illustrated in analysis of health system delivery

\footnotetext{
${ }^{4}$ Self-determination and autonomy over their own bodies
} 
across several Eastern European nations which considers how best to programme for this to be equitable (Shankland \& MacGregor, 2018). Efforts to tackle inequity often emphasise inclusion understanding this in health systems in terms of coverage, with a focus on identifying and reaching populations that currently lack access. There is increasing awareness that inclusion is not only about the possibility of access but also the actual terms of access, as well as the quality of care on offer for different people. It is therefore important to think about the causes of exclusion (from health and other, services). In addition to physical accessibility, poorer people may be excluded by the costs of accessing care (both financial and in terms of time), by health systems factors related to the organisation of care or stigmatising attitudes, and by language and other social barriers that may exclude people who are members of ethnic and religious minorities. Efforts to guarantee equity and inclusion face not only technical and material challenges but also social and political ones, especially in relation to governance and accountability (Shankland \& MacGregor, 2018):

- key factors in governance issues in wider society, decentralisation or corruption for example, can affect the structure and functioning of the health system.

- health care providers' attitudes and behaviour often play a major role in determining whether people from the target population trust them and willingly seek care.

- each programme has its own management and governance arrangements to direct the implementation process; at best these arrangements can help to strengthen equity and inclusion by modelling more inclusive and responsive governance

- $\quad$ key actors within government must make resource allocations that are sufficient to deliver more equitable impact (gender equality policy needs resources for programming)

- building participation and voice of future users into programme design mechanisms decision-making will allow for better programming and adaptation.

Broadly the literature illustrates gaps between women's rights, their representation and collective voice, and the real level of gender equality that is enjoyed in various domains. These disparities offer opportunities to redress these. Power (and impetus) to influence changes, and for these to be sustained, may come from women themselves, from external supporters (such as diaspora groups or foreign donors) or from internal authority at community and state levels. Or a combination of all three. Nonetheless gaps remain and stable situations can unravel into conflict with equality gains quickly becoming lost. Several international legal standards are adopted and passed into law, without women necessarily having the protection these describe (CEDAW ${ }^{5}$ for example, while domestic and GBV remain a priority for attention across the region). Near equal levels of literacy and outstanding areas of education (such as in STEM subjects) ${ }^{6}$ still do not lead to equal engagement of women and men in all work sectors; nor to equal levels of pay or seniority within organisations. In some situations of conflict, women have played an active role in peacebuilding yet still find their efforts to build stability thwarted by political forces or degeneration into further conflicts.

\footnotetext{
${ }^{5}$ Convention on the Elimination of All Forms of Discrimination

${ }^{6}$ Science, technology, engineering, and maths - where women students were numerous in the Soviet era.
} 


\section{Opportunities for Eastern neighbourhood countries}

\section{Tackling adverse norms and promoting positive role models in employment culture and practice is a major opportunity to address women's economic empowerment}

Women across eastern neighbourhood countries do not enjoy equal access to paid work.

Significantly less women than men take part in the labour market. For example, women are 54\% of the working age population of Armenia, yet only $40 \%$ of these women are employed or looking for work (IAAP, 2018). Azerbaijan is an exception as female labour force participation rates has caught up with male rates (Khitarishvili, 2016). Gender difference in participation is greatest among the 25-34 age-group, with childcare responsibilities likely to explain this (World Bank, 2016). Responsibilities of family care fall unequally on women and discourage and dis-incentivise even educated women from seeking employment options outside the home. In work, women are employed to a much greater extent in services and state sectors with significantly lower wages than in the sectors employing many males. Women have been hit far harder than men with unemployment and a host of problems associated with privatisation following the collapse of the USSR. Thus, for example Armenia has the highest unemployment rate among women $17.3 \%$ in 2018) in all post-Soviet countries (ILO cited in Zeimer, 2020: 84).

The gender pay gap remains high and can be as much as $50 \%$. Women generally receive the same level of tertiary education as men and make up almost half the workforce ${ }^{7}$. But if holding the same position at the same point in their careers the woman earns about $36 \%$ less per year than the man in South Caucasus countries (World Bank, 2018). Women also encounter cultural and sociological barriers in their access to managerial positions (Gabriel, 2016). Limited opportunities for women in the workforce reduce GDP ${ }^{8}$ and there is further negative impact when citizens and workers leave the country is steady numbers, depleting the labour force. In rural areas many women lacking other possibilities, tend to accept low-paid jobs in agriculture, often without official registration and without any social security rights. Eradicating inequalities between men and women in agriculture could help ensure equal access to employment for men and women, as well as equal pay for work of equal value (Gabriel,2016: 5).

The foundation of the economy varies across countries of the eastern neighbourhood so active measures to improve women's economic empowerment and address inequality must vary with context. The region contains energy-exporting countries (Azerbaijan), agriculture-dependent economies (Armenia, Georgia, Moldova) and relatively diversified economies with a stronger industrial sector (Belarus) (Khitarishvili, 2016). Agriculture employs at least $30 \%$ of the female and male workforce in all countries except Belarus but makes a relatively low contribution to economic output. That low productivity agriculture is pervasive throughout the region is therefore a constraint to improving economic power of those working in this sector.

Where the level of industrialisation is low, waged employment is restricted. Self-employment is important in Moldova and the Southern Caucasus and appears to be linked to the relative size of

\footnotetext{
7 Across Armenia, Azerbaijan and Georgia

8 By as much as $14 \%$ in Armenia, World Bank information cited by International Association of Applied Psychology (IAAP)
} 
the agriculture sector in these countries (Khitarishvili, 2016: 13). Private sector employment with a high share of self-employment or contributing family workers is indicative of entrepreneurial activity in both formal and informal sectors. Women are substantially engaged in entrepreneurial activities across all countries of the region (except for Armenia and Azerbaijan) with formal ownership of their business at one-third or higher. ${ }^{9}$ This is in line or higher than the OECD average, suggesting that women find more favourable economic outcomes from running their own entrepreneurial activity over waged employment. These female managed firms tend to be smaller in size and to hire proportionately more full-time female workers than male managed firms which are larger. Expansion of female managed firms might benefit these economically and generate more female jobs (Khitarishvili, 2016: 17). More work is needed to understand why women are less likely than men to establish firms with employees, become larger in size, and function in the formal sector and, more generally, how to support women to turn entrepreneurship of necessity into opportunity from entrepreneurship (Khitarishvili, 2016: 21).

\section{Building assets - digital, financial, property and information - can improve women's participation in small enterprise and informal sector employment}

Access to credit is one factor that may hinder the establishment and growth of female-owned businesses. Women in Moldova and Ukraine report greater difficulties in accessing credit and tend to draw on their personal networks more than men in obtaining credit for establishing or expanding their business (Khitarishvili, 2016). Weaker networks, and the lack of business knowledge are additional constraints that female-headed businesses face. Alleviating these constraints can increase the potential for employment growth via the expansion of female-owned businesses (Khitarishvili, 2016). Even in economies where women are substantially employed in agriculture as farm owners (as in Azerbaijan) these women identify asset deficits as constraints to developing farm-related enterprises: (i) lack of financial support, (ii) lack of knowledge of rules on trade and commercialization, and (iii) limited training opportunities to acquire these skills (Asian Development Bank, 2019a).

Gender differences in the ownership and control of property are major determinants of gender inequality; this includes ownership of a mobile phone and internet access. In Azerbaijan, $41 \%$ of women entrepreneurs surveyed (ADB, 2019: 102) had internet-capable mobile phones, but only $16 \%$ activated the internet services on their phones. Of the $16 \%$, only $6 \%$ used these services for entrepreneurial purposes. While $55 \%$ of women entrepreneurs had a computer, only $27 \%$ were using it for entrepreneurial activities. Lack of understanding on how the internet could help them in business was the main reason for not fully using it. In analysis of how to strengthen gender equality in Azerbaijan, the Asian Development Bank highlights opportunities to integrate gender equality within the Government's ICT strategy and proposes concrete measures including to: develop pilot programmes to support information and communication technology use among women entrepreneurs; increase women's access to online business development services and to support the development of e-commerce services for women entrepreneurs, in partnership with the private sector - providing credit or assistance to create websites so that women could engage more directly in e-commerce (ADB, 2019: 104).

\footnotetext{
${ }^{9}$ World Bank Enterprise Survey data cited in (Khitarishvili, 2016: 15).
} 
Increasing women's participation in the renewable energy sector is a further specific opportunity to improve access to affordable energy, new sector jobs and their use of this as a productive asset. Globally women tend to value new and efficient energy technology - it can free up their time for other more productive work and bring benefits to the household economy if energy costs are reduced (ADB, 2015: 93). Women in Armenia are interested in using renewable sources of energy, do not have sufficient social or financial capital to initiate such changes yet have potential to act as agents of change. Considering Armenia's dependence on natural gas from the Russian Federation, and the impact of price hikes on the population that is already living below the poverty line, concerns about this have potential to impact upon stability. Price increases would raise the cost of food and other goods and have the potential to heighten dissatisfaction with the government (ADB, 2015: 94). As well as forming a substantial part of a growing market for energy efficient technology there is potential to engage with women through supporting their participation in renewable energy projects. Renewable energy is "a more open field for women, as knowledge and technology transfer to the community is at an early stage in most developing countries." (ADB, 2015: 94).

\section{Ensuring legal protection, addressing GBV and reforming discriminatory laws is essential to promoting gender equality}

To address disparity between women's right to protection and the extent to which women are truly able to gain protection when they need it, there is opportunity to strengthen strategic and regulatory frameworks; promote women to higher levels within public sector employment and in representative Government and improve women's access to justice and the court system (OECD, 2019 b). Violence against women is a pervasive issue across the region: 17\% of women have suffered physical and/or sexual violence from an intimate partner at least once in their lifetime, and up to $46 \%$ in Moldova (OECD, 2019a). In several countries, female victims of domestic violence rarely reach out to courts due to resistance from family members and lack of trust in the judicial system. The lack of affordable legal systems ${ }^{10}$ is also harmful for those in chronically vulnerable positions, especially women and children. Access to such services is weakest in rural areas, where social beliefs perpetuate harmful attitudes towards men beating their wives, ${ }^{11}$ rape within marriage and economic violence. Access to such services is weakest in rural areas, where social beliefs perpetuate harmful attitudes towards men beating their wives, ${ }^{12}$ rape within marriage and economic violence (OECD, 2019a). Women who do leave their abusers face numerous problems, including that they have a hard time enrolling as students in school and finding work or education, families deny them resources, and they do not have access to property. The lack of a support system causes many to stay in these abusive relationships ${ }^{13}$ (IAAP, 2017).

Legal rights may not always be equally accessed and the support of third parties is often essential for women to obtain their rights. Even though women and men have the same rights to initiate divorce and the same requirements to finalise the process in Azerbaijan, divorcees face

\footnotetext{
${ }^{10}$ In Armenia \& Georgia underfunding of existing legal schemes is a common phenomenon (OECD, 2019b).

11 This is highest in Azerbaijan

12 This is highest in Azerbaijan

${ }^{13}$ Case study from Armenia
} 
social stigmas and judicial barriers. Women filing for divorce must anticipate condemnation of their families, lack of support from them and long court battles for children and property. Legal aid for divorced women and legal aid to support victims of domestic violence to go through a divorce, is provided by The Society for the Defence of Women's Rights (SDWR), an association of 24 women's non-governmental organisations (OECD, 2019a). Training and awareness raising about violence against women and girls (VAWG) among the population, health workers and law enforcement officers would be an opportunity to drive equality and bring social understanding and norms closer to the legal rights enshrined already (UNFPA, 2015: 8).

Adequate training for law-enforcement staff and health and social workers is vital to develop capacities that can actively prevent VAWG and guarantee access to justice and services for victims and survivors. The Police Academy of Georgia, for example, has specialised training courses on domestic violence with specialised programmes for patrol police officers and also for patrol-inspectors, district inspectors, and detective-investigators (UNFPA, 2015: 10). Providing courses for adolescents in schools and colleges on gender roles and expectations of family relationships is a pre-emptive way of addressing these issues. This can lead to important shifts in attitude, most notably the high proportion of students who stop believing that a woman must tolerate violence to keep their family together. ${ }^{14}$

\section{Strengthening women's visibility, developing collective voice and representation, recognising women's contribution to peace building may secure fragile gender gains}

The lives of women in the South Caucasus are subject to tensions between tradition and social change. After the collapse of the Soviet Union there was some reversion to traditional gender norms, because of the socio-economic hardship that followed and failure of Soviet gender equality policies. At the same time, feminist narratives made their way to the South Caucasus, inspiring social transformation and women's activism (Ziemer, 2020). Gains have been made even though women's role and influence in society is highly prone to change during periods of civic unrest or outright conflict. Recent literature considers how women in the South Caucasus operate in the face of interethnic conflicts, economic transition or security dilemmas and examines practices through which women adapt to conflict-ridden societies while attempting to foster social change (Ziemer, 2020).

Social movements are an opportunity which have the potential to either reproduce or transform existing gender inequalities, structures, and social belief systems. During the weeks of wide scale but non-violent protest in Armenia (2018) that became known as the Velvet Revolution the common goal of overturning an oligarchic and a corrupt government served to unite all types of women - both feminist activists and women with more 'traditional' gender role self-perceptions. The protest movement promoted values of national inclusivity and unified women although gender equality and feminist causes were not explicit aims of the protest movement. The shared experience for women protestors meant that for the first time ever, women were occupying political spaces previously reserved for men and acting as strategists, organisers and active

\footnotetext{
14 https://blogs.worldbank.org/europeandcentralasia/adolescents-gender-roles-and-intimate-partnerrelationships-moldova
} 
participants in the movement, as well as having discussions about gender roles and equal rights. This caused a shift in social perceptions of gender roles. Previously in a patriarchal society such as Armenia's women's 'proper role' was confined to being self-sacrificing mothers, praised for their ability to produce future soldiers, while men were expected to be the 'defenders of the nation' against the enemy (despite the peaceful character of the protests) (Ziemer, 2020: 73). Outside influences have used situations as they develop in country to promote and support women's agency. The break-up of the Soviet Union created opportunities for the international donor community to promote democratic values through support to already established groups and organisations, and to help develop new organisations with the goal of fostering an open and democratic civil society (in Georgia, Azerbaijan, and Armenia) (Abrahamyan et al, 2018). There are now thousands of non-governmental organizations (NGOs) pursuing social justice goals in a focus on women's issues and women's rights, and on peacebuilding and conflict resolution or transformation. Cardenas goes further to introduce the concept of women-to-women diplomacy as a particular form of bottom-up peacebuilding and its use through the experiences of women's organisations in Georgia. These grassroots organisations offer opportunities for peacebuilding through women-to-women diplomacy. Common ground for cooperation and inter-ethnic dialogue is identified with coalition building based around a common goal of achieving equal rights (Cardenas, 2019).

Azerbaijan is distinct in terms of poles of influence because of its links to Muslim states. In the post Arab Spring era of mediatized connectivity and collective political engagement, Azerbaijani women participate in different online and offline social and political movements and have been exposed to ideas of using flash mobs, a tactic employed mainly by liberal activists. This has emerged as a promising way to overcome the normative nature of Azerbaijani patriarchal society. (Mehrabov, 2016) The opportunity for internalising the feeling of being on the street and acting in concert with others and normalising this might lead towards an increasing participation of (especially young) women in the political processes of the country.

Women's involvement in civil society and civic activism does not easily translate into representation in formal politics - so opportunities for agency and expression are not fully realised. In Georgia, for example, although women were active in civil society prior to and during the Rose Revolution (2003), this activism did not translate into representation for female legislators in the post-Revolution parliament (Chkeidze 2017, cited in Ziemer, 2020: 80). To address this challenge there has been some use of quotas in representative government. Quota action could be an opportunity but is not an ultimate solution to gender-balanced representation, though it may in some circumstances positively influence women's political representation and leadership. In Armenia a female party-list quota of $15 \%$ was introduced to ensure women's engagement in elections (2007) and increased to 20\% (2011) Yet after 20 years of independence (1991-2011), the number of women in Armenia's legislature increased by only $7 \%$ and in 2018 , stood at $18 \%$ : three quarters of the global average of $24 \%$ (Ziemer, 2020: 77 ). Women self-withdraw; are likely to be disproportionately disadvantaged where elections are not free and fair; and when existing 'dirty' rules of the game played in Armenia's political life were not part of women's political culture many women find alternative spaces in civil society to express their political activism, away from formal politics (Ziemer, 2020: 78). 


\section{Examples of programmes designed to affect change in gender equality}

Below are some recent programmes targeting gender inequalities in the region. The list is not exhaustive and there is a lack of available data that considers implementation progress and impact. This review was tasked to assess evidence for any contribution to stability from initiatives to address gender equality. Besides the lack of assessments of programme impact the companion review (Carter, 2020) also concludes that it

- did not find systematic analysis of the links between perceptions of gender inequalities and perceptions of the legitimacy of governments in the region

- did not find research looking systematically at how the individual characteristics and trends of gender inequalities in the region's economies contribute to instability

- nor of work exploring the links between interpersonal SGBV and impacts on stability at community or national levels.

So although it is reasonable to expect that gender inequality might be a contributing factor to instability these reviews have not found evidence from the literature to support this, nor to demonstrate how supporting gender equality contributes to stability.

Achieving strong gender equality outcomes requires adequate, sustained financing in support of gender equality and women's empowerment. Despite rising levels of overseas development assistance (ODA) overall, the major part of this is allocated to cover programmes that include gender equality as a significant objective (ie gender mainstreaming such as improving women's access to health and education services). Support for focused programmes dedicated to gender equality and women's empowerment as their principal objective trails significantly in terms of funding allocations (OECD, 2018). Overall, donors are failing to effectively implement the twintrack approach ${ }^{15}$ that is recommended by the OECD Development Assistance Committee (DAC) and should increase support for dedicated programmes with gender equality and women's empowerment as a principal objective. Sweden and the Netherlands perform best in addressing this target (OECD, 2018: 6) and are a significant donor to the Eastern Neighbourhood.

Adoption of national action plans to address UN Security Council resolutions on women, peace and security (WPS) provide high level frameworks designed to address women's participation in decision making and peace negotiations, and in prevention of violence against women and girls (including sexual, domestic and gender-based violence) ${ }^{16}$. Over the past 20 years, these have been increasingly adopted and using a whole of government approach ${ }^{17}$ is the most realistic way forward for the effective implementation of the WPS agenda. Among countries with a whole of government approach to their NAP are Georgia, Moldova and Ukraine (Hamilton et al, 2020: 10). Responsibility for implementation of the WPS agenda lies with the state but the level of civil society involvement in the production and implementation of the Plan is important. Lack of sustainable funding presents significant challenges to the implementation of the WPS agenda

\footnotetext{
${ }^{15}$ An approach that combines gender mainstreaming into all programmes, with a second track of specific programming where gender equality is the main objective

${ }^{16}$ As for example 2018-2020 National Action Plan of Georgia for Implementation of the UN Security Council

Resolutions on Women, Peace and Security

17 No specific department is named as author or lead, and collegiate working is fostered
} 
(Hamilton et al, 2020:15). In particular, adequate funding for civil society organisations that are implicated in delivery. Systemic approaches to M\&E frameworks are a critical factor for assessing meaningful action on WPS (Hamilton et al, 2020:19) and these are not always robust. There are intersections of violence that do not start or end with situations of armed conflict and gender inequalities and gender-based violence cannot be adequately addressed if these are omitted from analysis and approach.

The OECD has long championed gender equality and has developed gender-specific instruments to provide a framework for policy action. These include Recommendation on Gender Equality in Education, Employment and Entrepreneurship (2013) and Recommendation on Gender Equality in Public Life (2015). These provide policy principles, guidelines and concrete measures to advance gender equality. The OECD has also developed gender policy toolkits, such as Mainstreaming and Implementing Gender Equality, and prepares regular gender reviews to track progress (OECD, 2019). Although designed as generic, global tools these have been used in some parts of the region.

Other programmes targeting gender inequalities in the region are listed below. The list is not exhaustive and there is a lack of available data that considers implementation progress and impact. This makes it hard to assess evidence for change to gender inequalities and if these were to have been achieved, whether that has in turn contributed to stability.

The Eastern Partnership (EaP) is a joint policy initiative which aims to deepen and strengthen relations between the European Union (EU), its Member States and its six eastern neighbours: Armenia, Azerbaijan, Belarus, Georgia, Moldova and Ukraine ${ }^{18}$. Joint commitments to deliver tangible results for citizens across the region cover four main priority areas:

- $\quad$ Stronger Economy (economic development and market opportunities)

- $\quad$ Stronger Governance (strengthening institutions and good governance)

- $\quad$ Stronger Connectivity (connectivity, energy efficiency, environment and climate change)

- $\quad$ Stronger Society (mobility and people-to-people contacts).

Structured engagement with a wide range of civil society organisations, furthers gender equality and non-discrimination. The EU (within the Eastern Partnership Scheme) works on digital connectivity ${ }^{19}$ to provide a better digital environment and increase job opportunities. Areas of current emphasis include strengthening government systems, cybersecurity and platforms for access, and these are expected to create more jobs in the digital industry.

UN Women and UNFPA, together with the European Union (EU), launched a three-year regional programme (July 2020) to tackle gender stereotypes and gender-based violence in six countries of the Eastern Partnership: Armenia, Azerbaijan, Belarus, Georgia, Moldova, and Ukraine. ${ }^{20}$ This programme is designed to engage a wide range of government bodies, civil society organisations, and individuals using strategies to challenge structural gender barriers and norms, with particular emphasis on transforming gender-stereotyped behaviour, strengthening men's

\footnotetext{
18 https://ec.europa.eu/neighbourhood-enlargement/neighbourhood/eastern-partnership_en

19 https://ec.europa.eu/neighbourhood-enlargement/sites/default/files/eap-factsheet-2019.pdf

20 https://eca.unwomen.org/en/news/stories/2020/7/press-release-un-women-unfpa-and-eu-launch-ambitiousinitiative\#
} 
involvement in parenting and domestic responsibilities, increasing men's access to parental leave, and reducing the number of people affected by gender-based violence through prevention interventions with potential perpetrators.

Women's Economic Empowerment in the South Caucasus (WEESC) is a three-year regional project aimed at supporting poor and socially excluded women in Armenia, Azerbaijan and Georgia to gain economic independence and participate in local decision-making. Launched in 2018 by UN Women, the Swiss Agency for Development and Cooperation (SDC) and the Austrian Development Agency (ADA) the project supports women in selected regions across all three countries - improving their capacities and skills, access to information and essential services. $^{21}$

Women in Politics in Moldova is a UN Women - UNDP initiative funded by the Government of Sweden, which supports capacity building of women in politics and awareness-raising campaigns regarding women's contribution to the political process. ${ }^{22}$ In partnership with the civil society organisations East-Europe Foundation (EEF) and the Centre Partnership for Development (CPD), Enhancing Women's Political Representation through improved capacity and enhanced support in Moldova, works to increase women's participation in Moldova politics and decisionmaking. It promotes increased public awareness of women's contributions to political leadership and public and business life and supports the Government of Moldova as it implements its commitments to women's rights.

Sustainable and Resilient Communities through Women Empowerment is a 3-year UNDP programme (2020-23) targeting rural women in Moldova who are more vulnerable to climate change and absolute poverty. The programme builds sustainable and inclusive resilient communities through empowering women to practice alternative livelihoods. In the context of increased environmental degradation and vulnerabilities to extreme weather patterns, environment-friendly and climate resilient practices and projects implemented by women headed households, women agri-producers and communities are expected to develop resilience to climate change (UNDP, 2020).

\section{References}

Abrahamyan, M., Mammadova, P., \& Tskhvariashvili, S. (2018). Women challenging gender norms and patriarchal values in peacebuilding and conflict transformation across the South

Caucasus. Journal of Conflict Transformation, Caucasus Edition, 3(1), 46-72.

http://caucasusedition.net/wp-content/uploads/2019/01/CHALLENGING-GENDER-NORMS-

DEALING-WITH-THE-PAST-AND-PROTECTING-THE-ENVIRONMENT-Community-Driven-ConflictTransformation-in-the-South-Caucasus-1. pdf\#page $=47$

Asian Development Bank (2019) Azerbaijan Country Gender Assessment

\footnotetext{
${ }^{21} \mathrm{https}: / / g e o r g i a . u n w o m e n . o r g / e n / n e w s / s t o r i e s / 2018 / 12 /$ womens-economic-empowerment-in-the-southcaucasus

22 https://eca.unwomen.org/en/where-we-are/moldova/leadership-and-political-participation/women-in-politics
} 
https://www.adb.org/sites/default/files/institutional-document/546166/azerbaijan-country-genderassessment-2019.pdf

Asian Development Bank (2015) Armenia Country Gender Assessment

https://www.adb.org/sites/default/files/institutional-document/162152/arm-country-gender-

assessment.pdf

Cardenas, M.L., (2019) Women-to-Women Diplomacy in Georgia: A Peacebuilding Strategy in Frozen Conflict

https://doi.org/10.1080/13698249.2019.1667713

Gabriel, M., (2016) European Parliament report on rights of women in the Eastern Partnership States (2016/2060(INI)

https://www.europarl.europa.eu/doceo/document/A-8-2016-0365_EN.pdf

Hamilton, C., Naam, N., \& Shepherd, L. J. (2020) Twenty years of Women, Peace and Security National Action Plans: Analysis and Lessons Learned

http://eprints.Ise.ac.uk/103952/1/Shepherd_twenty_years_women_peace_security_national_acti on_plans_published.pdf

IAAP (2017) Economic Empowerment of Women: Lessons from Armenia: Panel Discussion at the Non-Governmental Organization (NGO) Forum, United Nations Commission on the Status of Women

https://iaapsy.org/

Khitarishvili, T., (2016) Gender dimensions of inequality in the countries of Central Asia, South Caucasus, and Western CIS, Working Paper, No. 858, Levy

Economics Institute of Bard College, Annandale-on-Hudson, NY

https://www.econstor.eu/bitstream/10419/173467/1/wp_858.pdf

Mehrabov, I., (2016) Azerbaijani Women, Online Mediatized Activism and Offline Mass

Mobilization MDPI abstract Soc. Sci. 2016, 5(4), 60;

https://www.mdpi.com/2076-0760/5/4/60/htm

OECD (2015) Europe and Central Asia SIGI Regional Report

https://www.oecd.org/dev/development-gender/SIGI-BrochureECA-2015-web.pdf

OECD (2018) Aid to gender equality and women's empowerment: An overview https://www.oecd.org/dac/gender-development/Aid-to-gender-overview-2018.pdf

OECD (2019a). SIGI 2019 Regional Report for Eurasia. Social Institutions and Gender Index.

Paris: OECD Publishing. https://doi.org/10.1787/f6dfa21d-en

OECD (2019b) Social Institutions and Gender Index, SIGI 2019 Global Report Annex A

https://www.oecd-ilibrary.org/sites/bc56d212-

en/1/3/1/index.html?itemld=/content/publication/bc56d212-

en\&_csp_=3c7e048c80fc5e8e6616e1289a989dd3\&itemIGO=oecd\&itemContentType=book\#ann ex-d1e11652 
OECD (2019c) Promoting Gender Equality in Eurasia Better Policies for Women's Economic Empowerment

https://www.oecd.org/eurasia-week/Promoting-Gender-Equality-Eurasia-Feb2019.pdf

Shankland, A. \& MacGregor, H. (2018) Equity and Inclusion in Health Programming, SDC-IDS Briefing Note 6, Brighton: IDS

https://opendocs.ids.ac.uk/opendocs/bitstream/handle/20.500.12413/14038/SDC-

IDS\%20BriefingNote\%2006_Alex_final_final.pdf?sequence=1\&isAllowed=

UNDP Moldova (2020) Sustainable and Resilient Communities through Women Empowerment https://www.md.undp.org/content/moldova/en/home/projects/sustainable-resilient-communitiesthrough-women-empowerment.html

UNFPA (2015) Combatting violence against women and girls in Eastern Europe and Central Asia Issue brief No. 6

https://eeca.unfpa.org/sites/default/files/pub-pdf/21770\%20Brief_web.pdf

UN WOMEN (2017) UN Secretary Generals High level panel on women's economic empowerment

https://hlp-wee.unwomen.org/en/about/seven-drivers

World Bank Gender Data portal

http://datatopics.worldbank.org/gender/home

World Bank (2016) Armenia Country Gender Assessment

http://documents1.worldbank.org/curated/en/250481491242159715/pdf/

World Bank (2018) Why we Care about Closing Gender Wage Gaps in the South Caucasus https://www.worldbank.org/en/news/opinion/2019/03/07/why-we-care-about-closing-genderwage-gaps-in-the-south-caucasus

Zeimer (2020) Women Against Authoritarianism: Agency and Political Protest in Armenia U. Ziemer (ed.), Women's Everyday Lives in War and Peace in the South Caucasus, https://doi.org/10.1007/978-3-030-25517-6_4

\section{Acknowledgements}

We thank the following expert who voluntarily provided suggestions for relevant literature or other advice to the author to support the preparation of this report. The content of the report does not necessarily reflect the opinions of any of the experts consulted.

- Ulrike Ziemer, University of Winchester 


\section{Suggested citation}

Enfield, S. (2021). Promoting gender equality in the Eastern Neighbourhood region. K4D

Helpdesk Report. Brighton, UK: Institute of Development Studies. DOI: 10.19088/K4D.2021.063

\section{About this report}

This report is based on six days of desk-based research. The K4D research helpdesk provides rapid syntheses of a selection of recent relevant literature and international expert thinking in response to specific questions relating to international development. For any enquiries, contact helpdesk@k4d.info.

K4D services are provided by a consortium of leading organisations working in international development, led by the Institute of Development Studies (IDS), with Education Development Trust, Itad, University of Leeds Nuffield Centre for International Health and Development, Liverpool School of Tropical Medicine (LSTM), University of Birmingham International Development Department (IDD) and the University of Manchester Humanitarian and Conflict Response Institute (HCRI).

This report was prepared for the UK Government's Foreign, Commonwealth and Development Office (FCDO) and its partners in support of pro-poor programmes. Except where otherwise stated, it is licensed for non-commercial purposes under the terms of the Open Government Licence v3.0. K4D cannot be held responsible for errors, omissions or any consequences arising from the use of information contained in this report. Any views and opinions expressed do not necessarily reflect those of FCDO, K4D or any other contributing organisation.

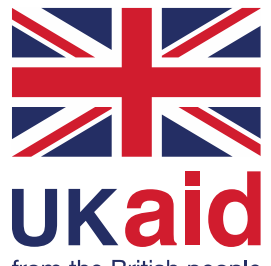

(c) Crown copyright 2021. 